\title{
Indoor Thermal Environment of Temporary Mobile Energy Shelter Houses (MeSHs) in South Korea
}

\author{
Jeong-Gook Kim ${ }^{1}$, Junghun Lee ${ }^{1}$, Byung-Lip Ahn ${ }^{2}$, Hwayeon Shin ${ }^{3}$, Seunghwan Yoo ${ }^{2}$, \\ Cheol-Yong Jang ${ }^{2}$, Doosam Song ${ }^{1}$ and Jonghun Kim ${ }^{2, *}$
}

1 Department of Architectural Engineering, Sungkyunkwan University, Suwon KS002, Republic of Korea; E-Mails: kjk1568@gmail.com (J.-G.K.); junghun@kier.re.kr (J.L.); dssong@skku.edu (D.S.)

2 Energy Saving Laboratory, Korea Institute of Energy Research, Daejeon KS015, Republic of Korea; E-Mails: ahnbr@kier.re.kr (B.-L.A.); shyoo@kier.re.kr (S.Y.); cyjang@kier.re.kr (C.-Y.J.)

3 Qualification Development \& Certification Laboratory, Korea Productivity Center, Seoul KS013, Republic of Korea; E-Mail: hyshin@kpcqa.or.kr

* Author to whom correspondence should be addressed; E-Mail: jonghun@kier.re.kr; Tel.: +82-042-860-3467; Fax: +82-042-860-3202.

Academic Editor: Nyuk Wong

Received: 24 August 2015 / Accepted: 28 September 2015 / Published: 7 October 2015

\begin{abstract}
Temporary housing must be developed to support the long-term residence needs of disaster victims. The present study assesses a temporary housing unit, the so-called Mobile Energy Shelter House (MeSH), incorporating the "Korean Dwelling Insulation Standard" in order to reduce energy usage for cooling and heating. To assess energy performance, the characteristics of the indoor thermal environment were measured during the winter and summer seasons. In summer, at maximum insolation, the outdoor temperature was $37.6{ }^{\circ} \mathrm{C}$ and the indoor temperature of the $\mathrm{MeSH}$ ranged from 18 to $24{ }^{\circ} \mathrm{C}$ when the cooling system was not used. Conversely, during winter, the average outdoor temperature was $-11.3{ }^{\circ} \mathrm{C}$ and the indoor temperature ranged from 16.09 to $20.63{ }^{\circ} \mathrm{C}$ when a temperature-controlled floor-heating was installed. Furthermore, the Predicted Mean Vote (PMV) was adopted to determine whether the ISO 7730 comfort criterion (i.e., PMV range from -0.5 to +0.5 ) was achieved. Based on the calculations presented here, PMV in summer ranged from -1.21 to +1.07 and that in winter ranged from -0.08 to -0.85 , suggesting that the thermal environment is not always comfortable for occupants in either summer or winter. Nevertheless, the ISO comfort criterion can be achieved through varying
\end{abstract}


air velocity in summer and changing clothing characteristics in winter. A comparison between yearly energy demand of existing characteristic temporary housing (Shelter House) and the MeSH modules used in this study was performed. The simulation results show a $60 \%$ difference in energy demand between $\mathrm{MeSH}$ and existing temporary housing shelter houses.

Keywords: natural disaster; emergency relief; temporary housing; indoor thermal environment; predicted mean votes; energy efficiency

\section{Introduction}

Extensive research has been conducted on issues related to post-disaster temporary housing [1-5]. The number of natural disasters has increased markedly in recent decades [6], having a considerable impact on the built environment. In disaster scenarios, most buildings suffer extensive damage, many collapse entirely, and the destruction of homes is one of the most visible effects of a disaster, resulting in large numbers of homeless people [7].

The United Nations Disaster Relief Coordinator has advised that, in order to restore the livelihoods of affected communities, post-disaster reconstruction programs should start as soon as possible [8]. Housing provision plays a crucial role in such programs since it is one of the most important human needs and is essential to well-being [9]. A house is a space for people to live in, providing conditions for family life, comfort, protection, and privacy. Disaster relief efforts should prioritize the need for housing, because the loss of a house involves more than physical deprivation; it represents the loss of dignity, identity, and privacy $[3,4,10,11]$.

Providing housing is a fundamental step toward establishing some sense of normalcy in the life of the affected community; and in limiting the death toll and the spread of diseases by providing for personal hygiene and protection against external factors such as inclement weather.

Although the provision of shelters is widely accepted as a necessary component of response and recovery following disasters such as earthquake, hurricanes, tsunamis, and floods, it is not yet clear which type of shelter is best as in certain cases shelter implementation has been hindered by inappropriate climate, cultural differences, poorly located settings, camp-related social issues, expenses, overcrowding, poor services, and delays [6,11-13]. In addition, the design of shelters may potentially provide an unacceptable standard of living. Lastly, in some cases, it has also been difficult to recover shelters for future storage and re-use [14].

However, post-disaster scenarios include a range of factors that might result in inadequate solutions, mainly due to the need for rapid and large-scale action under chaotic conditions [10], and previous studies have presented many problems related to post-disaster housing [15]. As a consequence, disaster housing solutions very often fail to achieve their objectives [16-18].

In Korea, there was considerable loss of property as a result of Typhoon "Rusa" in 2002, with approximately 1720 houses being demolished or damaged. Accordingly, shelter houses were required for displaced residents, and 1510 temporary housing units were provided by the national government [7]. Unfortunately, these temporary houses were simply commercial container boxes, which are unsuitable 
for permanent accommodation [16]. Eight years after the typhoon, 33 housing units were destroyed during the bombardment of Yeonpyeong Island in 2010, and temporary houses were donated by a non-governmental association known as "Hope Bridge". These temporary housing units each have a net residential floor area of $18 \mathrm{~m}^{2}$, and consist of a living and sleeping room, toilet, and kitchen. Nevertheless, despite offering improvements over previous shelter housing, these temporary houses proved too small to house people in comfort [17]. Accordingly, more appropriate shelter housing is urgently required.

This study presents a plan for a temporary house, termed the Mobile Energy Shelter House; $\mathrm{MeSH}[18,19]$. After creating a prototype $\mathrm{MeSH}$, indoor thermal performance was measured in summer and winter. Based on the findings, we synthesized performance, measured temperature and PMV, and investigated the viability of this type of temporary housing [20].

\section{Methodlogy}

\subsection{Description of Mobile Energy Shelter House (MeSH)}

The MeSH have to be loadable onto vehicles for rapid deployment [21]. Therefore, road width is the main constraint on the floor area of MeSH. The road conditions are a width of $2.75 \mathrm{~m}$ and height of $4.2 \mathrm{~m}$. The vehicle dimensions used are: width $2.5 \mathrm{~m}$, depth $16.7 \mathrm{~m}$, height $4.0 \mathrm{~m}$, and weight 40 tons. These dimensions are established by the Road Traffic Act in South Korea, so the maximum width of the floor area is designed to be $3.0 \mathrm{~m}$ considering a safety factor and basic module unit of $30 \mathrm{~cm}$ [22].

The module use is based on double occupancy and includes a Room module (RM), Toilet module (TM), and Kitchen module (KM), and each module can be arranged variously according to the family structure. The area of the RM is $18 \mathrm{~m}^{2}$, that of the TM is $4.5 \mathrm{~m}^{2}$, and the KM is $9 \mathrm{~m}^{2}$. The overall area of the MeSH is $31.5 \mathrm{~m}^{2}$ and a corridor in located on the bottom of the module to allow easy access to each room. Figure 1 shows the basic exterior of a MeSH and its corresponding floor plan [23].

(a)

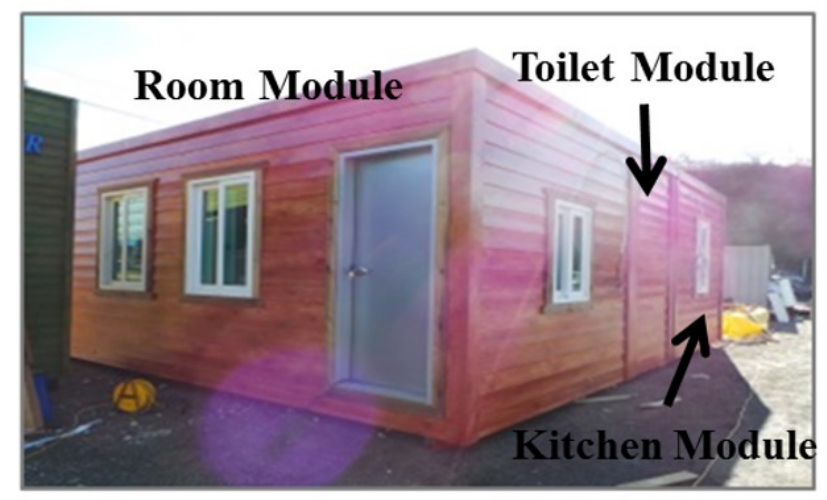

(b)

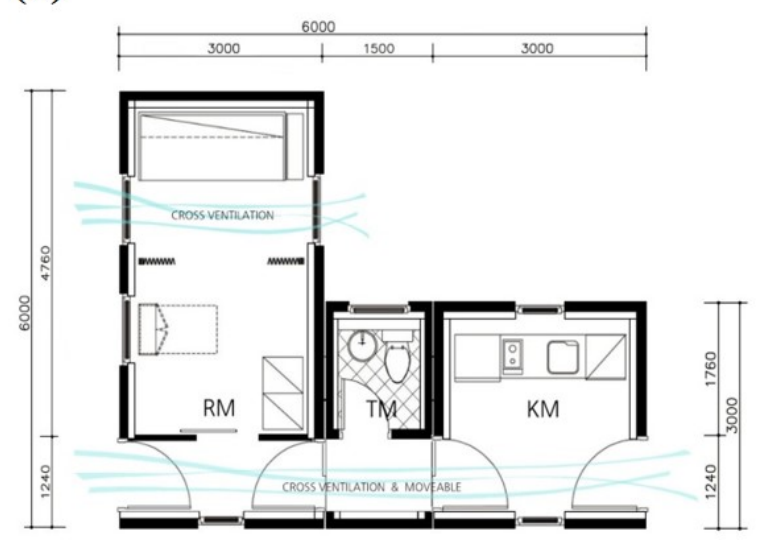

Figure 1. Schematic view of Mobile Energy Shelter House (MeSH) module: (a) Placement of an emergency shelter house; (b) MeSH floor plan.

In the "Minimum Residential Standard" defined by Ministry of Land, Infrastructure and Transport in South Korea, a single room with one single bed requires a floor area of $7.8-8.63 \mathrm{~m}^{2}$; a room with a 
double bed requires $8.12-8.88 \mathrm{~m}^{2}$; a room with two single beds requires $9.62-11.48 \mathrm{~m}^{2}$. A toilet area is set to $2.4-2.88 \mathrm{~m}^{2}$ considering the toilet seat, basin, and shower facility as the minimum facilities and the size of area for using the facility should be $2.43 \mathrm{~m}^{2}$ [22]. A basic floor plan, as shown in Figure 1, is based on a two-member family, but the MeSH can accommodate more than two people by adjusting the number of modules. The U-value of the exterior wall is $0.31 \mathrm{~W} / \mathrm{m}^{2} \cdot \mathrm{K}$, of windows is $1.8 \mathrm{~W} / \mathrm{m}^{2} \cdot \mathrm{K}$, the door is $2.7 \mathrm{~W} / \mathrm{m}^{2} \cdot \mathrm{K}$, roof is $0.18 \mathrm{~W} / \mathrm{m}^{2} \cdot \mathrm{K}$, and floor is $0.23 \mathrm{~W} / \mathrm{m}^{2} \cdot \mathrm{K}$, as shown in Table A1.

\subsection{Field Measurements}

The investigated MeSH units were located in Mu-ju, which is situated in the center of South Korea and has average summer temperature and humidity for South Korea. In summer 2014, the daily average temperature was $23.3{ }^{\circ} \mathrm{C}$, with maximum and minimum temperatures of 35.5 and $14.0^{\circ} \mathrm{C}$, respectively. In winter, the average daily temperature was $0.9{ }^{\circ} \mathrm{C}$, with maximum and minimum temperatures of 18.3 and $-13.9{ }^{\circ} \mathrm{C}$, respectively.

Temperature, humidity and the Predicted Mean Vote (PMV) were measured to determine the indoor thermal environment performance of MeSH modules in Mu-ju [24]. To examine the indoor thermal environment of the RM, we measured indoor temperature and relative humidity using a T-type thermocouple equipped with a data logger (HP 34970A (Agilent Technologies, USA) and TR-72UI (T\&R corporation, USA) [25].

Indoor environmental quality and thermal comfort depend on several physical, physiological, and psychological factors. Here, the indoor thermal environment was quantified using the measured data, and based on the PMV, which was calculated with six body heat environment factors (temperature, air flow, humidity, mean radiant temperature, activity, amount of clothing) according to Equation (1) [24]:

$$
\begin{aligned}
\mathrm{PMV} & =\left(0.303 e^{-0.036 M}+0.028\right)\left\{\left(M-W-3.05 \times 10^{-3}\right) \times\left[5773-6.99(M-W)-p_{a}\right]\right. \\
& =-0.42[(\mathrm{M}-\mathrm{W})-58.15]-1.7 \times 10^{-5} M\left(5867-p_{a}\right)-0.0014 M\left(34-t_{a}\right) \\
& \left.=-3.96 \times 10^{-8} f_{c l} \times\left[\left(t_{c l}+273\right)^{4}-\left(\overline{t_{r}}+273\right)^{4}\right]-f_{c l} h_{c}\left(t_{c l}-t_{a}\right)\right\}
\end{aligned}
$$

Here, $M$ denotes the metabolic rate $\left(\mathrm{W} / \mathrm{m}^{2}\right)$ of the body's surface area; $\mathrm{W}$ is external work $\left(\mathrm{W} / \mathrm{m}^{2}\right)$, which is equal to zero for most activities; $f_{c l}$ is the ratio of an individual's mean surface area while clothed, to that while unclothed; $t_{a}$ is the air temperature $\left({ }^{\circ} \mathrm{C}\right) ; \overline{t_{r}}$ is the mean radiant temperature $\left({ }^{\circ} \mathrm{C}\right) ; p_{a}$ is the partial water vapor pressure $\left(p_{a}\right) ; h_{c}$ is the convective heat transfer coefficient $\left(\mathrm{W} / \mathrm{m}^{2} \cdot{ }^{\circ} \mathrm{C}\right)$; and $t_{c l}$ is the surface temperature of clothing $\left({ }^{\circ} \mathrm{C}\right)$.

The PMV value is calculated from the above expression and then compared to the ISO7730 comfort standard to evaluate the thermal sensation (Table 1) [24].

Table 1. Seven-point Predicted Mean Vote (PMV) scale of comfortable thermal range.

\begin{tabular}{ccccccc}
\hline Cold & Cool & Slightly Cool & Neutral & Slightly Warm & Warm & Hot \\
\hline-3 & -2 & -1 & 0 & +1 & +2 & +3 \\
\hline
\end{tabular}

We used information on metabolic activity (met) and clothing (clo) in accordance with the ASHRE Handbook [26]. In particular, metabolic activity was assumed to depend on the activities performed during the day, and we considered resting activity to correspond to $1.2 \mathrm{met}$ (equal in summer and winter). 
The values used for met and clo are shown in Table 2. Finally, temperature, air velocity, humidity, and radiant temperature were measured using an AM-101 PMV meter.

Table 2. Thermal comfort conditions, metabolic activity, and clothing parameters used in model.

\begin{tabular}{ccccc}
\hline Activity & \multicolumn{4}{c}{ Clothing } \\
\hline & Summer season & \multicolumn{3}{c}{ Winter season } \\
& Underwear & 0.04 & Underwear & 0.04 \\
Sit or Stand and Rest 1.2 & Top wear & 0.14 & Top wear & 0.20 \\
& T-shirt (short) & 0.19 & T-shirt (Tick) & 0.34 \\
& Trousers (thin) & 0.15 & Pants (Tick) & 0.24 \\
& Socks & 0.03 & Socks & 0.03 \\
metabolic activity (met) $\left(69.6 \mathrm{~W} / \mathrm{m}^{2}\right)$ & 0.55 clothing $(\mathrm{clo})\left(0.085 \mathrm{~m}^{2} \cdot \mathrm{K} / \mathrm{W}\right)$ & 1.21 clo $\left(0.186 \mathrm{~m}^{2} \cdot \mathrm{K} / \mathrm{W}\right)$ \\
\hline
\end{tabular}

RM air temperature was measured at heights of $0.3,1.2$, and $2.1 \mathrm{~m}$. The floor surface $(0 \mathrm{~m})$ and ceiling surface $(2.4 \mathrm{~m})$ were also selected as measuring points for indoor temperature, although the representative indoor temperature for the $\mathrm{RM}$ was assumed to occur at the center point (i.e., at $1.2 \mathrm{~m}$ height). In total, 43 thermocouples were installed within the RM. All RM data were obtained within a time interval of $15 \mathrm{~min}$ at the measurement points shown in Figure 2. Indoor temperature distributions were examined in the horizontal and vertical planes.
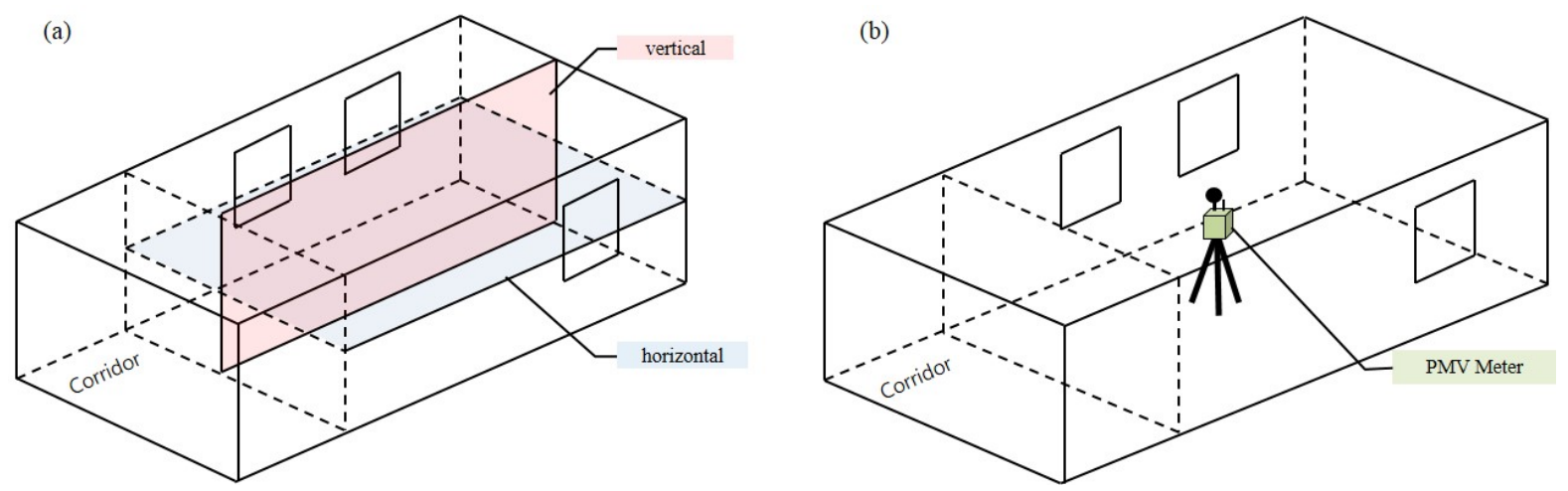

Figure 2. Measurement on thermal performance: (a) Measurement axis; (b) Measurement of Predicted Mean Vote (PMV).

\section{Results and Discussion}

\subsection{Indoor and Outdoor Temperature and Humidity}

The summer season in South Korea is characterized by high temperature and humidity. Consequently, it was important to control temperature and humidity through ventilation as in the MeSH air-conditioning equipment is not installed. Therefore, temperature and humidity in the RM module were measured to ensure compliance with the "thermal comfort zone" defined by ASHRAE [26].

The measurements show that the MeSH was affected considerably by outdoor conditions, as the units have no cooling system. At $08: 00$, the indoor temperature of $17.5^{\circ} \mathrm{C}$ was similar to that outdoors, but 
the outdoor temperature can reach $37.6{ }^{\circ} \mathrm{C}$. Meanwhile the indoor temperature is $22.9{ }^{\circ} \mathrm{C}$ and it corresponds to the thermal comfort zone. Relative humidity was nearly 100\% at 08:00 and decreased with increasing temperature. At 11:37, when the temperature peaked, the minimum relative humidity was $30.2 \%$.

The difference between indoor and outdoor daytime temperatures is influenced by solar irradiance during the daytime but it decreases after sunset. Furthermore, the relative humidity decreases depending on the temperature rise. The RM module did not exceed $28.3^{\circ} \mathrm{C}$ under cross ventilation conditions even when affected by outdoor conditions and the relative humidity corresponds to the humidity comfort zone after 11:00.

Therefore, the MeSH developed by this research corresponds to the "thermal comfort zone" represented by ASHRAE during the more than $60 \%$ of the daylight hours even though a cooling system is not installed. The interior environment of the RM module was determined to be similar to the summer relative humidity and thermal comfort zone conditions recommended by ASHRAE [27].

The indoor temperature distributions within the RM module at 08:00, 14:00, and 16:00 in 2 August 2014 for the summer season were measured in the vertical and horizontal planes, as shown in Figure 3. In the vertical plane, Figure 4, temperature increased over time and with closer proximity to the ceiling. The temperature of the ceiling relative to the floor is increased by solar irradiance. Due to the storage of heat by the structure, the overall indoor temperature distribution at $16: 00$ is approximately $1{ }^{\circ} \mathrm{C}$ warmer than at 12:00 when the highest outdoor temperature occurs. In the horizontal plane, temperature increased over time and with closer proximity to the window than the corridor. The RM modules include a window on both side walls at the same position for cross-ventilation, which serves to lower the indoor temperature. Furthermore, the wall of RM module contiguous with the TM module is affected by outdoor conditions, and the temperature of the RM wall directly facing outdoor is highly influenced by outdoor conditions.

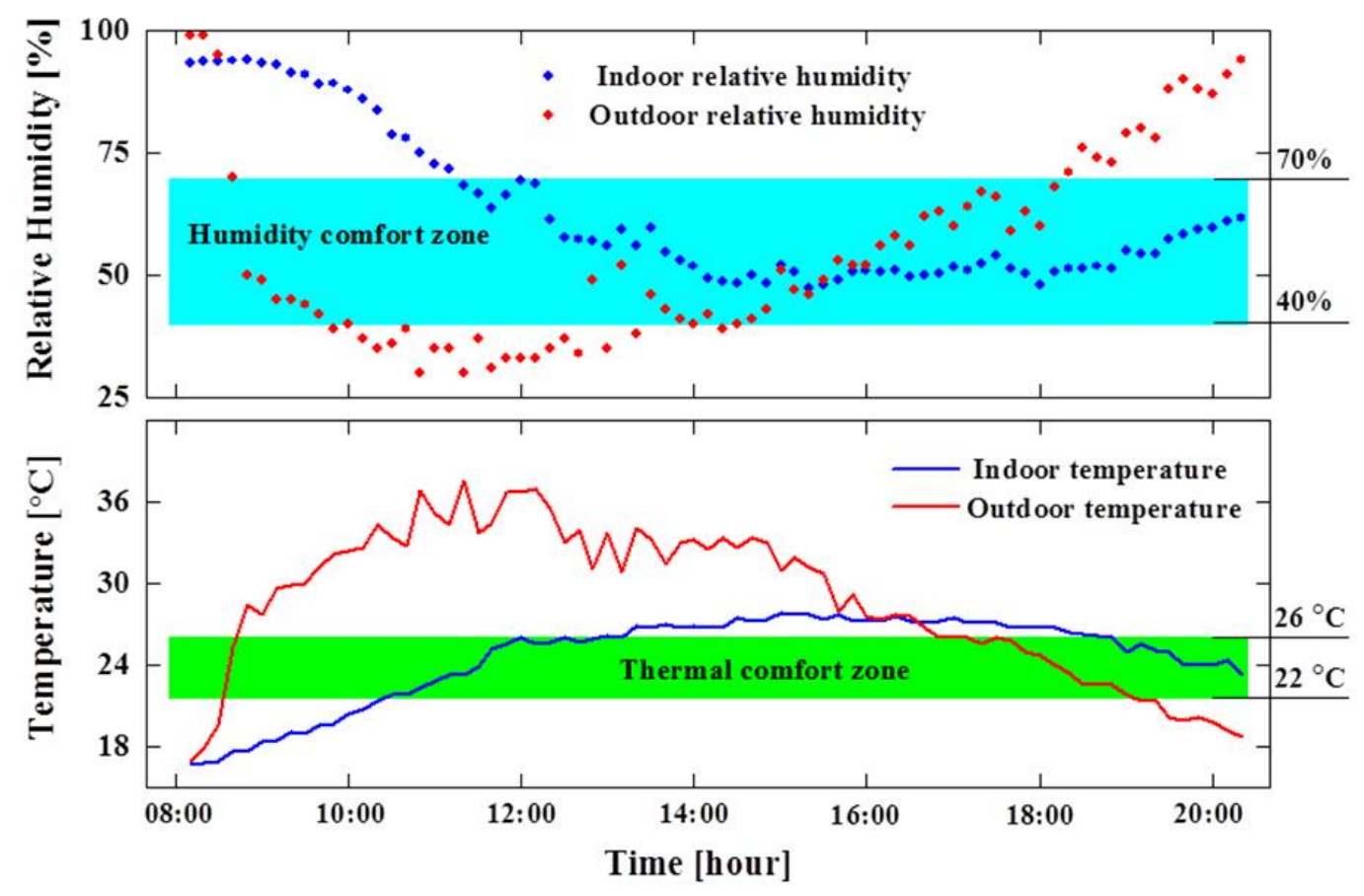

Figure 3. Thermal performance with humidity and thermal comfort zone in summer. 

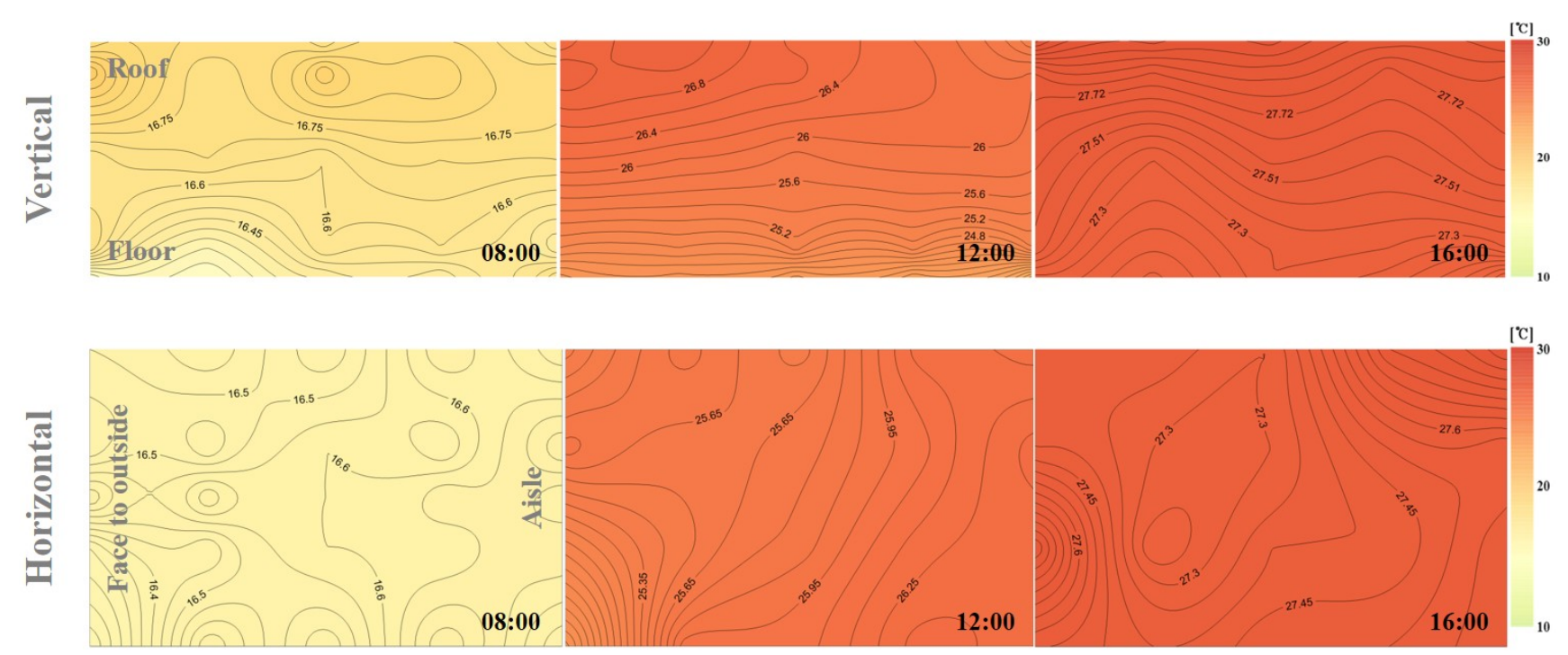

Figure 4. Temperature distribution of Room module (RM) module in summer.

The winter climate in South Korea is cold and dry. Therefore, the RM modules include an electric panel for floor heating to control temperature and humidity; these parameters were measured on 9 January 2015 from 20:00 to 08:00 when the temperature was low in order to confirm the thermal comfort zone. Thus the room temperature is not influenced by outdoor conditions.

At 20:00, the measured temperatures were $-9.3{ }^{\circ} \mathrm{C}$ outdoors and $19.9{ }^{\circ} \mathrm{C}$ indoors. Although the outdoor temperature dropped to $-12.2^{\circ} \mathrm{C}$, the indoor temperature remained between 16.2 and $21.5^{\circ} \mathrm{C}$. More than $80 \%$ of the measurement period complied with the ASHRAE "thermal comfort zone" range of 18 to $24{ }^{\circ} \mathrm{C}$. Relative humidity measurements began at 08:00 and were $9.1 \%$ outdoors and $30.4 \%$ indoors. Outdoor relative humidity represents dry conditions not exceeding $30 \%$, but indoor relative humidity reached $75 \%$ and corresponded to the "humidity comfort zone" over $85 \%$ of the measurement period. The electric panel used in this research set the indoor temperature at $20{ }^{\circ} \mathrm{C}$ and on/off control was applied. Therefore the heating was switched off when the temperature reached the set-point, as shown in Figure 5. Increasing the set-point temperature to $21^{\circ} \mathrm{C}$ resulted in a longer duration of time within the "temperature comfort zone" at night. Therefore, using the radiant floor-heating panel, the MeSH achieved the "thermal and humidity comfort zone" parameters for more than $80 \%$ of the night- time period.

The indoor temperature distribution in winter was measured in the vertical and horizontal planes at 20:00, 00:00, and 04:00, as shown in Figure 6. In the vertical plane, temperature declined over time and with closer proximity to the ceiling. The temperature of the floor was approximately $1.2{ }^{\circ} \mathrm{C}$ warmer than the ceiling, and the thermal performance of the door was $4.7 \mathrm{~W} / \mathrm{m}^{2} \cdot \mathrm{K}$, due to the influence of outdoor conditions. In the horizontal plane, temperature declined over time and with proximity to the window. The cross-ventilation effect of the RM module is beneficial in summer, but disadvantageous in winter, resulting in lower temperatures near the window. To address this issue, double-glazed window units with a thermal performance of $2.4 \mathrm{~W} / \mathrm{m}^{2} \cdot \mathrm{K}$ were installed to reduce heat exchange via the window. 


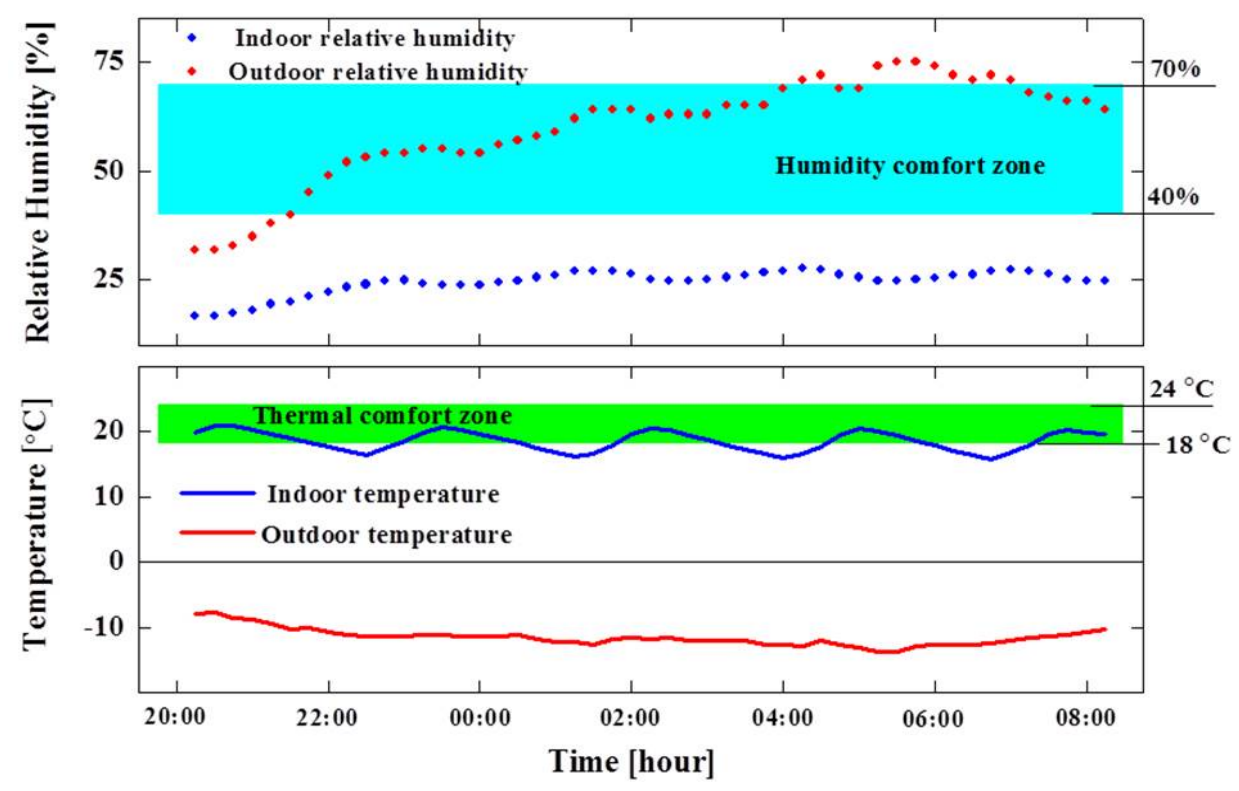

Figure 5. Thermal performance with humidity and thermal comfort zone in winter.
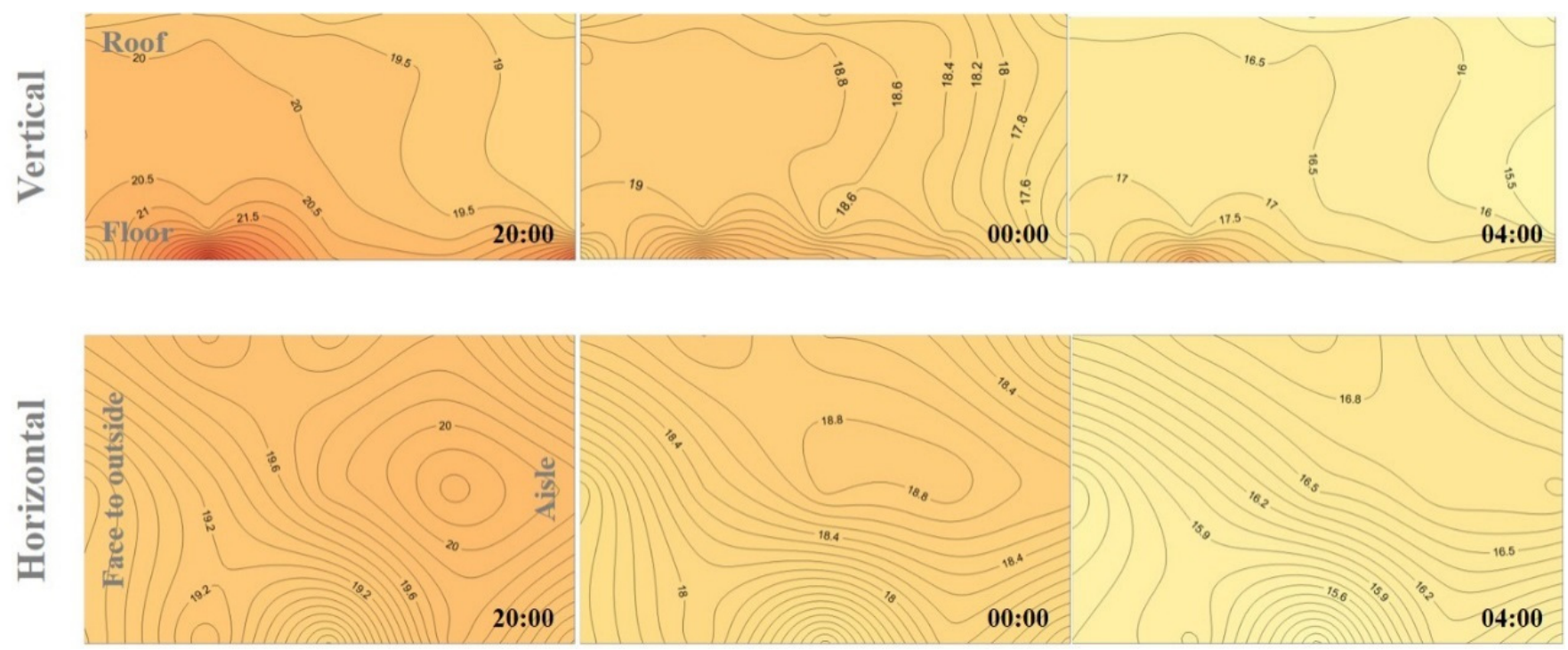

Figure 6. Temperature distribution of RM module in winter.

\subsection{Indoor Thermal Comfort through Predicted Mean Vote (PMV) Analysis}

The PMV factors used for the analysis were 0.55 clo (summer), 1.21 clo (winter) and 1.2 met (summer and winter). PMV was calculated based on the measured temperature, humidity, average radiant temperature, air velocity, metabolic activity, and clothing information. Data measured using the AM-101 PMV meter are shown in Table 3 [28].

Summer PMV values were within the range -1.21 to +1.07 (Figure 7). At 11:00, the PMV values met the ISO comfort criterion of -0.5 to +0.5 , whereas periods were outside the comfort zone range due to a lot of solar radiation. Conversely, between 08:00 and 11:00, the PMV values corresponded to a thermal comfort level of "slightly cool (i.e., -1)". Subsequently, the PMV values corresponded to thermals levels designated "slightly warm (i.e., +1)" until 19:00. 
Table 3. Data measured using the AM-101 PMV meter.

\begin{tabular}{ccc}
\hline Parameter & Summer Season & Winter Season \\
\hline Average temperature & $24.81^{\circ} \mathrm{C}$ & $18.99{ }^{\circ} \mathrm{C}$ \\
Average humidity & $62.55 \%$ & $24.51 \%$ \\
Average Mean Radiant & $24.15^{\circ} \mathrm{C}$ & $18.09{ }^{\circ} \mathrm{C}$ \\
Temperature (MRT) & $0.093 \mathrm{~m} / \mathrm{s}$ & $0.032 \mathrm{~m} / \mathrm{s}$ \\
Average velocity & -1.21 to +1.07 & -0.85 to -0.08 \\
PMV &
\end{tabular}

We assumed that the "slightly cool" PMV values can be addressed by changing the clothing characteristics, whereas "slightly warm" values can be addressed by changes in air velocity. Cooling fans used in Korea operate at an average speed of 3 to $4 \mathrm{~m} / \mathrm{s}$. Setting a fan speed to a minimum of $3 \mathrm{~m} / \mathrm{s}$ resulted in a PMV of -0.04 . Therefore, during the summer season, PMV values can be expected to satisfy the ISO comfort of -0.5 to +0.5 solely by varying air velocity [26].

In winter, PMV values ranged from -0.85 to -0.08 and exhibited the same trend as indoor temperature, due to the floor-heating system incorporating temperature controllers set at $20^{\circ} \mathrm{C}$ (error range from -5 to $5^{\circ} \mathrm{C}$ ) with the temperature control device heating was outside the comfort range intermittently. However, most of the PMV values were within the ISO comfort range. The PMV value of the entire time must change the amount of clothing and heating equipment set temperature in order to enter in the comfort range. Increasing the set-value temperature from 20 to $21-22{ }^{\circ} \mathrm{C}$ ensures that the temperature is consistently within a comfortable range. However, when the internal temperature of the RM changes the set temperature, it is impossible to confirm the humidity, air flow, and radiation temperature. Thus, PMV was re-calculated by changing the types of clothing used in the calculation. For the value outside the comfortable range, we added to the amount of clothing a short-sleeved, short robe (thin) 0.34 to a value close to the little cold $(-1)$. We applied the changes in clothing characteristics described above to the PMV factor data point exhibiting the lowest value $(-0.85)$, which occurred at 03:45, and demonstrated that a PMV value of -0.38 could be achieved. During the winter season, access close ISO thermal comfort can be achieved by changing the amount of clothing.

\subsection{Predicted Energy Demand}

Energy analysis tools utilize numerical analysis methods such as finite difference and response coefficient to estimate the hourly energy balance of a building considering indoor and outdoor conditions and the heat storage load of the walls, which vary over time during the analysis period [28]. This study used the EnergyPlus simulation program, which was developed to integrate the advantages of DOE-2, BLAST, and COMIS. As such, it improves upon previous shortcomings such as incomplete indoor temperature predictions using thermal calculation algorithms for Conduction Transfer Function (CTF), Conduction Finite Difference (CFD) and Combined Heat and Moisture Transfer (HAMT) [29].

The EnergyPlus simulation used to compare advertised temporary housing with the MeSH modules used in this study was calculated with the existing yearly energy demand [30]. Occupant schedules and device usage, light heating, and outer conditions were entered in the same conditions, as shown in Figure A1 and Table A1 [31]. 
The simulation results (Figure 8) show a 60\% difference in energy demand between the MeSH $\left(108.49 \mathrm{kWh} /\left(\mathrm{m}^{2} \cdot\right.\right.$ year $\left.)\right)$ and the existing temporary housing Shelter House $\left(272.56 \mathrm{kWh} /\left(\mathrm{m}^{2} \cdot\right.\right.$ year $\left.)\right)$. Analysis of monthly energy demand shows a difference occurs in the winter, which confirms that more than about a two times heating energy demand difference occurs in January and December that have the lowest average temperature.

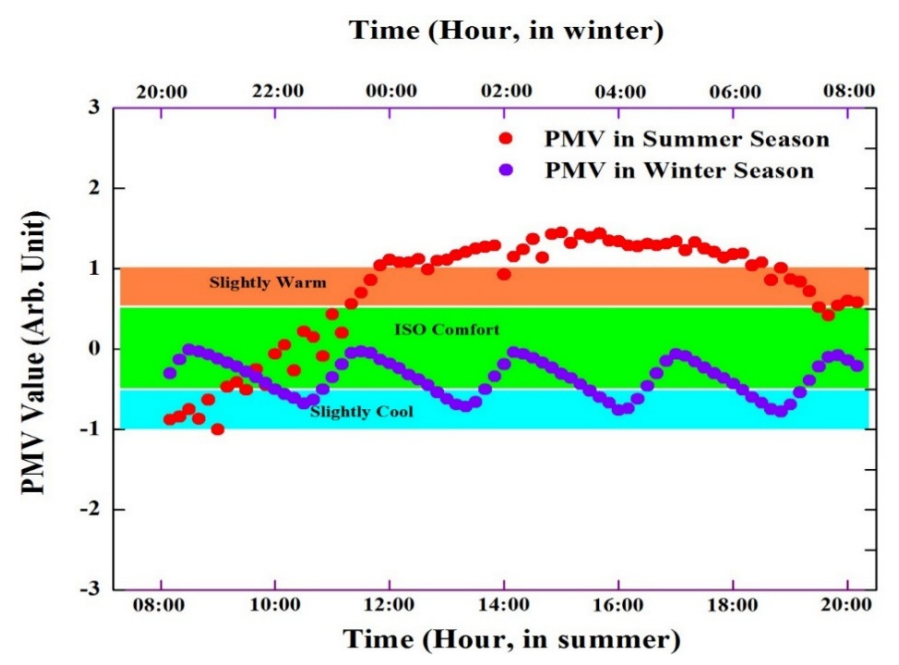

Figure 7. Comparison between PMV measurement and ISO comfort in summer and winter.

(a)

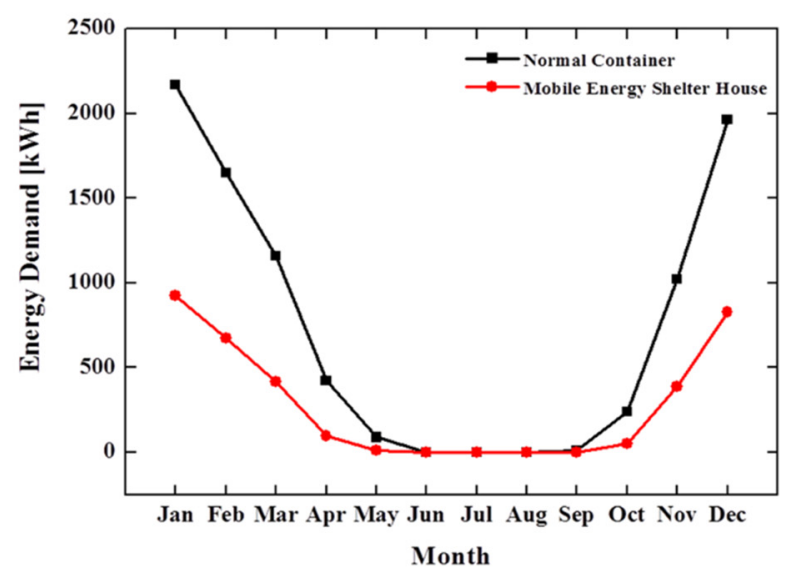

(b)

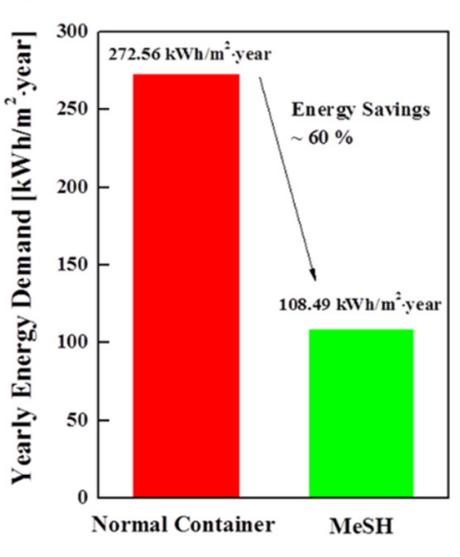

Figure 8. Simulated energy savings: (a) Monthly energy demand; (b) Yearly energy demand.

\section{Conclusions}

In this study, we investigated the thermal comfort of proposed temporary housing as a starting point for the development of housing solutions for residents displaced by natural disasters. We have developed the Mobile Energy Shelter House (MeSH) to be produced as a modular shelter, considering Korean standards in relation to dwelling space, insulation and so on. To test the $\mathrm{MeSH}$, we measured temperature and relative humidity and calculated PMV for both summer and winter. The results were used to evaluate indoor thermal performance and to estimate the energy demand of the MeSH.

In summer, the average indoor temperature was $23.68^{\circ} \mathrm{C}$ and average humidity was $60.64 \%$, meaning that even without installing a cooling system, approximately $70 \%$ of the period complies with the 
ASHRAE-defined comfort zone. In winter, the average indoor temperature was $18.51{ }^{\circ} \mathrm{C}$ and average humidity was $24.51 \%$, such that approximately $80 \%$ of the period complies with the comfort zone when a radiant floor-heating panel is used.

The thermal comfort index of +1 (slightly warm) can be achieved if fan speed is summer is increased to $3 \mathrm{~m} / \mathrm{s}$, and a thermal comfort index of -1 (slightly cool) in winter can be achieved at a clo value of 1.55 , both of which satisfy the conditions for the thermal comfort zone.

Analysis of energy demand showed that the MeSH was highly energy efficient when compared with existing emergency shelter designs. In monthly analysis results, differences in energy demand occurred more between existing shelters and MeSH. Especially, in January and December, the difference of energy demand was more than two times higher than for an existing shelter house. Yearly energy demand of the existing shelter design was estimated at $272.56 \mathrm{kWh} /\left(\mathrm{m}^{2} \cdot\right.$ year $)$, compared with which the MeSH design that achieved a $60 \%$ savings $\left(108.49 \mathrm{kWh} /\left(\mathrm{m}^{2} \cdot\right.\right.$ year $)$.

\section{Acknowledgements}

This work was conducted under the framework of the Research and Development Program of the Korea Institute of Energy Research (KIER) (B3-8413), and was supported by the National Research Foundation of Korea (NRF) grant funded by the Korea government (MSIP) (No.2011-0028075)

\section{Author Contributions}

All the authors were involved in preparing the manuscript. Jonghun Kim provided guidance and supervision. Jeong-Gook Kim implemented the main research, checked results, wrote the paper, and discussed the results. Junghun Lee, Byung-lip Ahn, Hwayeon Shin performed the experiment, Seunghwan Yoo designed the simulations, and Cheol-Yong Jang and Doosam Song reviewed the paper.

\section{Conflicts of Interest}

The authors declare no conflicts of interest.

\section{Appendix}

(a)

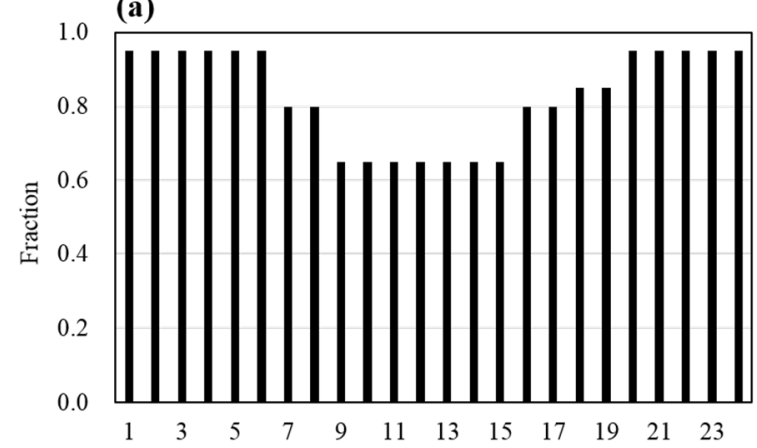

(b)

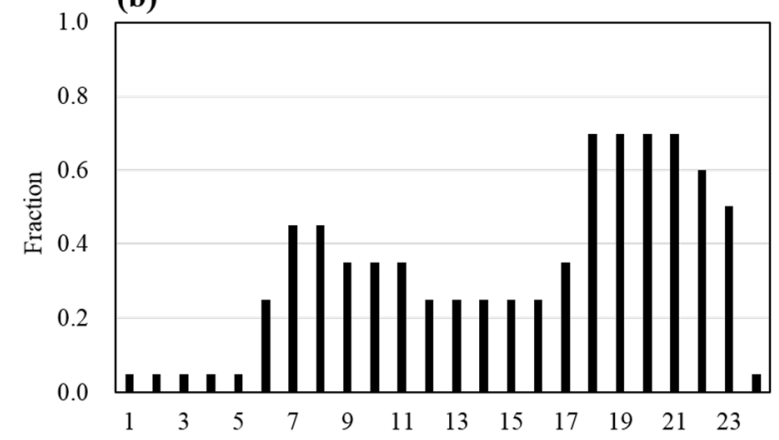


Figure A1. Cont.

(c)

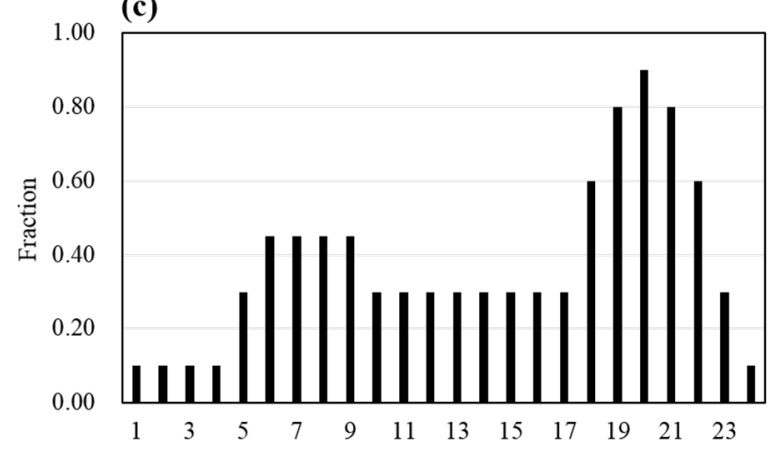

(d)

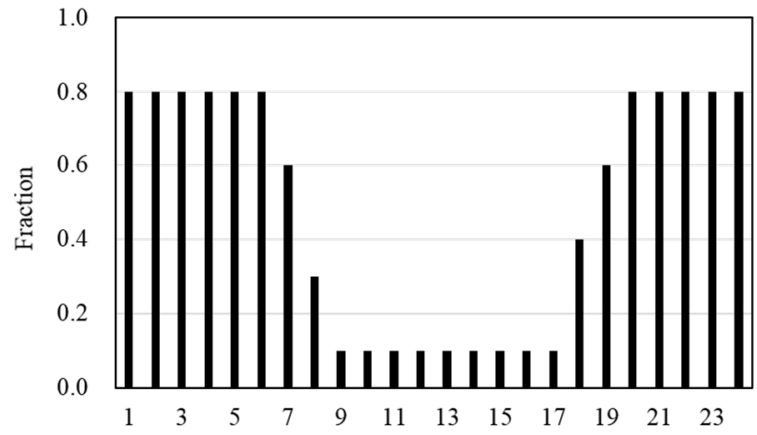

(e)

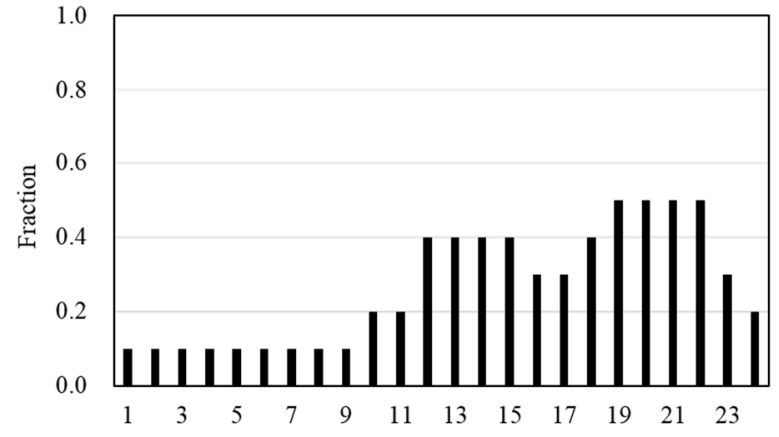

Figure A1. Hourly internal loads following various schedules: (a) Occupancy, (b) Indoor lights, (c) Equipment. The set temperatures for heating and cooling complied with the schedules: (d) Heating, (e) Cooling.

Table A1. MeSH specifications, internal heat gains, and thermal performance of the envelopes, and ventilation and infiltration rates for Energy Plus.

\begin{tabular}{|c|c|c|}
\hline \multicolumn{2}{|c|}{ Parameters } & Input values \\
\hline \multicolumn{2}{|c|}{ Location } & Daejeon, Republic of Korea $\left(36^{\circ} \mathrm{N}, 127^{\circ} \mathrm{E}\right)$ \\
\hline \multicolumn{2}{|c|}{ Number of floors } & 1 floor \\
\hline \multicolumn{2}{|c|}{ Net floor area } & $23.93 \mathrm{~m}^{2}$ \\
\hline \multirow{4}{*}{ Set temperature } & Heating temperature & 24 \\
\hline & Heating set-back temperature & 12 \\
\hline & Cooling temperature & 20 \\
\hline & Cooling set-back temperature & 28 \\
\hline \multirow{3}{*}{ Internal heat gains } & Equipment & $8.2 \mathrm{~W} / \mathrm{m}^{2}$ \\
\hline & Lights & $5.8 \mathrm{~W} / \mathrm{m}^{2}$ \\
\hline & Occupancy & 0.03 Person $/ \mathrm{m}^{2}$ \\
\hline \multirow{4}{*}{ U-values of envelopes } & Exterior wall & $0.31 \mathrm{~W} / \mathrm{m}^{2} \cdot \mathrm{K}$ \\
\hline & Roof & $0.18 \mathrm{~W} / \mathrm{m}^{2} \cdot \mathrm{K}$ \\
\hline & Floor & $0.23 \mathrm{~W} / \mathrm{m}^{2} \cdot \mathrm{K}$ \\
\hline & Window & $1.50 \mathrm{~W} / \mathrm{m}^{2} \cdot \mathrm{K}$ \\
\hline \multirow{2}{*}{ Air flow } & Ventilation rate & $0.51 \mathrm{~L} /\left(\mathrm{s} \cdot \mathrm{m}^{2}\right)$ (flow per exterior surface area) \\
\hline & Infiltration rate & $0.30 \mathrm{~L} /\left(\mathrm{s} \cdot \mathrm{m}^{2}\right)$ (flow per exterior surface area) \\
\hline
\end{tabular}




\section{References}

1. Johnson, C. Impacts of prefabricated temporary housing after disasters: 1999 earthquake on Turkey. Habitat Int. 2007, 31, 36-52.

2. Chan, R.C.K.; Yao, Y.M.; Zhao, S.X.B. Self-help housing for temporary population in Guangzhou, China. Habitat Int. 2003, 27, 16-35.

3. Fantozzi, F.; Galbiati, P.; Leccese, F.; Salvadori, G.; Rocca, M. Thermal analysis of the building envelope of lightweight temporary housing. J. Phys. Conf. Ser. 2014, 547, 491-502.

4. El-Anwar, O.; El-Rayes, K.; Elnashai, A. An automated system for optimizing post disaster housing allocation. Autom. Constr. 2009, 18, 983-993.

5. Felix, D.; Branco, J.M.; Feio, A. Temporary housing after disasters: A state of the art survey. Habitat Int. 2013, 40, 136-141.

6. National Disaster Information Center. Disaster yearbook, 2002-2012. Available online: http://www.safekorea.go.kr/ (accessed on 30 September 2015).

7. Arslan, H. Re-design, re-use and recycle of temporary houses. Build. Environ. 2007, 42, 400-406.

8. United Nations Disaster Relief Organization. Shelter after Disaster: Guidelines for Assistance; United Nations: New York, NY, USA, 1982.

9. Barakat, S. Housing Reconstruction after Conflict and Disaster; Overseas Development Institute: London, UK, 2003.

10. Caia, G.; Ventimiglia, F.; Maass, A. Container vs. dacha: The psychological effects of temporary housing characteristics on earthquake survivors. J. Environ. Psychol. 2010, 30, 60-66.

11. Nigg, J.M.; Barnshaw, J.; Torres, M.R. Hurricane Katrina and the flooding of New Orleans: Emergent issues in sheltering and temporary housing. Ann. Am. Acad. Pol Soc. Sci. 2006, 604, $113-128$.

12. Johnson, C.; Lizarralde, G.; Davidson, C.H. A system view of temporary housing projects in post-disaster reconstruction. Constr. Manag. Econ. 2006, 24, 367-378.

13. El-Anwar, O.; El-Rayes, K.; Elnashai, A. Optimizing large-scale temporary housing arrangements after natural disasters. J. Comput. Civil. Eng. 2009, 23, 110-118.

14. Arsalan, H.; Cosgun, N. The evaluation of temporary earthquake houses dismantling process in the context of building waste management. Available online: http://kocaeli2007.kocaeli.edu.tr/kocaeli 2007/TAM_METIN_NUMARALI-SIRALI-PDF/678-678.pdf (accessed on 30 September 2015).

15. Davidson, C.; Lizarralde, G.; Johnson, C. Myths and Realities of Prefabrication for Post-Disaster Reconstruction. In Proceedings of the 4th International i-Rec Conference, Christchurch, New Zealand, 30-2 May 2008.

16. Kronenburg, R.H. Mobile and flexible architecture: solutions for shelter and rebuilding in post-flood disaster situations. Available online: http://rice.iuav.it/351/1/KRONENBURG.pdf (accessed on 30 September 2015).

17. Park, Y.J. A research of actual conditions of temporal residence in stricken districts. Resid. Environ. Inst. Korea 2004, 2, 36-50.

18. Moon, J.I.; Song, Y.H.; Wang, W.C.; Lim, S.H. A study field examinations and interviews for Yeonpyeongdo temporary housing. J. Korean Hous. Assoc. 2012, 23, 21-28. 
19. Shin, H.Y.; Kim, J.G.; Kim, J.H. A study on mobile energy shelter house for emergency welfare. Archit. Inst. Korea 2012, 33, 357-358.

20. Hidayat, B.; Egbu, C. A literature review of the role of project management in post-disaster. In Proceedings of the 26th Annual ARCOM Conference: Association of Researchers in Construction Management, Leeds, UK, 6-8 September 2010; pp. 1269-1278.

21. Shin, H.Y.; Kim, J.G.; Kim, J.H.; Jeong, H.G.; Jang, C.Y.; Hong, W.H. Indoor thermal environment performance of mobile energy shelter house for emergency welfare. Soc. Air-conditioning Refrig. Eng. Korea 2014, 14, 355-358.

22. Minimum Dwelling Standard; under Residential Code Section 5; Ministry of Land, Infrastructure and Transport: Se-jong city, South Korea, 2011.

23. Arslan, H.; Cosgun, N. Reuse and recycle potentials of the temporary houses after occupancy: example of Duzce, Turkey. Build. Environ. 2008, 43, 702-709.

24. Ergonomics of the Thermal Environment; ISO7730; International Organization for Standardization: Geneva, Switzerland, 2005.

25. Song, Y.H.; Wang W.C.; Lim S.H. A study of temporary housing design with unit modular method. Archit Inst. Korea 2013, 3, 155-162.

26. ASHRAE Handbook: Fundamentals; American Society of Heating, Refrigerating and Air-Conditioning Engineers: Atlanta, GA, USA, 2013.

27. Johnson, C. What's the Big Deal about Temporary Housing? Planning Considerations for Temporary Accommodation after Disasters: Example of the 1999 Turkish Earthquake. In Proceedings of the 2002 TIEMS Disaster Management Conference, Waterloo, ON, Canada, 15-17 May 2002.

28. Cornaro, C.; Sapori, D.; Bucci, F.; Pierro, M.; Giammanco, C. Thermal performance analysis of an emergency shelter using dynamic building simulation. Energy Build. 2015, 88, 122-134.

29. Comité Européen de Normalisation (CEN). Indoor Environmental Input Parameters for Design and Assessment of Energy Performance of Buildings-Addressing Indoor Air Quality, Thermal Environment, Lighting and Acoustics: EN15251; CEN: Brussels, Belgium, 2007.

30. Heo, Y.; Choudhary, R.; Augenbroe, G.A. Calibration of building energy models for retrofit analysis under uncertainty. Energy Build. 2012, 47, 550-560.

31. Ahn, B.L.; Park, J.W.; Yoo, S.H.; Kim, J.H.; Jeong, H.J.; Leigh, S.B.; Jang, C.Y. Synergetic effect between lighting efficiency enhancement and building energy reduction using alternative thermal operating system of indoor LED lighting. Energies 2015, 8, 8736-8748.

(C) 2015 by the authors; licensee MDPI, Basel, Switzerland. This article is an open access article distributed under the terms and conditions of the Creative Commons Attribution license (http://creativecommons.org/licenses/by/4.0/). 